\title{
Chinese Curricula of Medical Science in the Context of Globalization
}

\author{
Jinyuan Zeng ${ }^{1}$ \\ ${ }^{1}$ School of Foreign Language Studies, Wenzhou Medical University, Wenzhou, Zhejiang, China \\ Correspondence: Jinyuan Zeng, School of Foreign Language Studies, Wenzhou Medical University, Chashan \\ university town, 325000, Wenzhou, Zhejiang, China.
}

Received: November 7, 2017

Accepted: March 26, 2018

Online Published: March 27, 2018

doi:10.5430/ijhe.v7n2p169

URL: https://doi.org/10.5430/ijhe.v7n2p169

\begin{abstract}
As China runs towards the forefront of global economic power, people begin to pay growing attention to the quality of life and medical education that play a significant role in sustaining the development by providing healthier labor force. It is evident that in the process of globalization new curricula in line with international standards top Chinese medical education agenda. Efforts have been made to plan the curricula of medical science with international dimensions that train physicians for the health of individuals. This paper analyzes the characteristics of medical curricula developed under new circumstances.
\end{abstract}

Keywords: Chinese higher education, globalization, curricula, medical science

\section{Introduction}

The implementation of reform and opening up policies designed by the late economic reformist Xiaoping Deng has accelerated the development of Chinese higher education in many aspects, including but not limited to curricula. Apart from the impact of policies on the development of education, higher education in the world has been internationalised, a predominant feature in four key aspects of educational changes which are also one part of the chain reaction (Green, 2006). Transnational contact in the circle of higher education has been frequent and post-modernism era has witnessed the shift of higher education from localization to internationalization. A good case in point: in May 2008, the Weill Cornel Medical College in Qatar, Cornel University's branch campus in the Middle East, celebrated the graduation of the first class of medical students who were awarded M.D. degrees by an American university (David and Antonio, 2013). It not only marked a milestone in global higher learning, but also posed numerous challenges and opportunities to local universities and colleges to internationalize their curricula in the hope that they would not lag behind or be eliminated.

Under these circumstances, curriculum framework is one aspect of Chinese tertiary education which needs attaching great importance to. Originally, the aim of higher education was to propagate the policies and ideology of communism as well as to cultivate people to dedicate themselves to the four modernizations (Mok, 2004). Therefore, the curricula were designed to fulfill that political goal aiming to guarantee social stability and prevent regime change. Nevertheless, the global economy develops to the extent that the old structure of curricula of higher education in China can't meet the challenges and satisfy the needs of the developing world. Consequently, curricula are sure to undergo a process of reform.

Furthermore, the premise that China ranks No.2 in terms of GDP in the world provides adequate financial support for China to promote its medical science which doesn't keep pace with the global medical development in the past decades. According to the statistics newly released by WHO, the average life span in China ranks in the middle among all the countries and territories due to its insufficient medical resources and underdeveloped medical technology. The fact results in the phenomenon that there is "patient drain"--some rich people seek medical service abroad.

In an effort to meet the challenges and seize the opportunities, Chinese central government has adopted a wide range of measures which aim at marketization, decentralization, autonomy, internationalization and curriculum reform. In spite of the outstanding performance that has been achieved in different facets, the curriculum of medical science is still under question on the ground that the shift from an elite to a "public-oriented" higher education system doesn't take full account of the specialized features of medical science. Therefore, it is of great necessity to put Chinese curricula of medical science under microscope (Huseyin, et al, 2015). The findings will present key features of Chinese curricula of medical science, which benefits curricula developers and teachers to increase the quality by 
offering diversified curriculum with international dimensions so that China can be on par with the global health standards.

\section{Globalization}

To the surprise of Theodre Levitt, who first came up with the concept of globalization in his book The Globalization of Markets in 1983, people from all walks of life have been debating its positive and negative effects and the extent to which it affects the globe in different aspects. Though the initial underlying implication, based on the definition by some scholars as 'international integration' or 'internationalization of production and commodity culture' (Al-Rodhan N.R.F \& Stoudmann G. 2006, Gibson-Graham, 2006), is from an economic perspective. "Medicine truly embodies the principles of globalization, as health issues traverse all borders" (Helena and Pauline, 2015, p. 38)

In addition to the influence of globalization on tertiary medical education, the concept of curriculum as a living breathing entity, and the curriculum should be dynamic rather than fixed (Abrahamson, 1978). It implies that not until the curriculum changes in response to the circumstances of society and the economy as well as the needs of its students can it prosper. It accords with what William \& Jeff (2010) propose that the relationship between economic development and education is symbiotic.

Curriculum development plays a significant role in functions through which the mission of medical schools is smoothly operationalized, which indicates that designing a reasonable curriculum has a key part to play in giving Chinese health care professionals more job satisfaction, a more fulfilling career and a more harmonious doctor-patient relationship.

From the perspective of postmodernism which underlies one part of the theoretical framework of this paper, three main elements of postmodern curriculum are identified as follows: (a) a focus on community cooperation rather than corporate competition, (b) a holistic process perspective rather than separate parts, and (c) a multilayered, interdisciplinary curriculum, which includes the integration of theology (Slattery, 2006, p. 108-109). In a bid to adapt to the changing environment, Chinese Education Department has revised the syllabus of medical science. The curriculum development has taken into account of advanced technologies and development of medical science in the employment market. In accordance with the revised teaching program, the majority of medical schools have incorporated a Global health module into the medical curricula that makes physicians more amenable to international practices, and adopted a curriculum framework that gives teachers the professional freedom concerning how to deliver the curriculum by using teaching strategies, the criteria and modes of assessment. Pragmatically, the autonomy that the medical schools and teachers have deals with the relationship between the intended curriculum and the implemented curriculum or smoothens out the conflict between the curriculum developers and the curriculum instructors (McKnight, 2000). As a result, the curriculum gap deriving from the compatibility among the intended curriculum, the actual curriculum and the achieved curriculum can be narrowed or even minimized to the full.

\section{The History of Medical Curricula}

Based on the standards of western medicine, medical curricula can be roughly categorized into four periods.

1) Period after Opium War(until 1922), which was founded on British and Japanese medical curricula.

2) Period of Northern warlords government (1912-1928), through which Japanese medical system plays a dominant role along with Chinese local characteristics,

3) Period of Nanjing National government, during which the curriculum provision has been broadened to 51 subjects,

4) Period after the foundation of P.R. China, during which medical education experiences the huge development.

Physicians educated in the first period failed to become qualified due to a lack of logistics and sufficient financial appropriation, delivery method, poor assessment and accreditation standards, flaws in the selection of medical learners, neglected research and a shortage of faculty development (Huang, 2012). However, medical curricula roughly took shape in this period which marked the shift from traditional Chinese medical science to western medicine. The characteristics in these four periods was discipline-based approach, which curriculum instructors thought was appropriate, and society-based medical education has not been laid emphasis on. Consequently, students were unable to quickly and eligibly deal with the cases of health problems that they would meet owing to the lack of past experience. 


\section{The Curricula of Medical Science in China}

\subsection{Goals}

The medical curricula aim at training students to: 1) receive quality medical learning in the tertiary institutions, possess solid basic medical theories, knowledge and skills, equip with health problem-solving competencies in medical field; 2) know the trends and directions of medical development, and be able to participate in community healthcare and health education; 3) have a broad scope of related scientific knowledge, especially of modern mathematics, physics, chemistry, life sciences and information technology, and be adept at using computers and intelligence information system; 4) have a good command of one or two foreign languages, communicate with foreign medical professionals and be able to obtain foreign medical information; 5) have extensive adaptive capacity, good expressive and interpersonal communicative competence; 6)own considerable basic knowledge of social sciences, particularly of economics, laws and history; 7) possess high professional ethics and serve people heart and soul (Huang, 2009).

\subsection{Content}

Under the guideline of medical curricula, teaching content in the form of lectures, labs, clinical skills tutorials, electronic resources etc can be divided into the following two aspects. First, educational content includes:

1) Basic medical sciences: medical education is founded on basic medical sciences which include but not limited to pathophysiology, genetics, cytobiology, biochemistry. These subjects are offered in the first two years of a medical program, and the medicine-related content of these sciences,

2) Clinical sciences: Clinical sciences are mainly made up of epidemiology, immunology, clinical microbiology, pharmacology, internal science, surgical science, oncology etc, the content of which are covered in medical education, and the professional content of these sciences,

3) Behavioral sciences: Content of information processing and psychobiology, social neuroscience, semantic networks, etc. related to health care,

4) Social sciences: Political science is covered as compulsory courses, including socialism, Situation and Policy, Marxism Basic Principles, Chinese Modern History and Military Theory. In addition, sociology, economics, demography, etc are covered as electives, and the content of these sciences

Apart from information on medicine as a science, education content related to medical practices, professional skills and codes, values and professionalism is also offered to integrate the relevant content to the whole medical education process for the purpose of training physicians to be professionally competent, the components of which include: communication skills, interpersonal relations and teamwork, social and cultural values and responsibilities, etc (Balcioglu, 2015).

\subsection{Methods of Teaching}

In an attempt to train qualified physicians with integrated professional skills and competencies instead of discrete competencies and isolated skills sets in ever changing contexts, teachers in medical schools have added a variety of teaching methods. Traditional lecture-based teaching is not any more the only important means adopted by the faculties to deliver the knowledge. This approach helps learners acquire short-term retention of content and is limited in gaining critical thinking (Stranger-Hall, 2012).

In trying to mitigate this disadvantage of lectures, problem-based learning (PBL) has been introduced into the classroom setting, which aims to educate physicians equipped with critical thinking in medical field and marks a milestone in teaching medical education in China. Different from teacher-centered approach characterized by lecture-based learning, PBL is student-centered and exposes students to the real world problems common in the medical education, through which they learn the content. In other words, PBL is in contrast to lecture-based learning, where the content is introduced in advance of the problem, which plays a significant role in cultivating medical students to be critical thinkers and team collaborators in the processing of solving problems(Agbeh, 2014).

When it comes to medical education, policy-makers, curriculum developers and teachers increasingly use holistic approach that can be seen as a method for students to achieve a wide range of techniques and scientific foundations and evidence, and is highlighted in all stages related to healthcare. The theoretical framework of delivery model is based on humanism and constructivist theory (McGrath, 2007). 
There are other teaching methods, including seminars, workshops, small group tutorials, discussions, task-based learning, visiting, demonstrations, bedside instruction and so on that are an indispensable part of teaching models in medical education.

\subsection{Assessment}

Assessment as a process of gathering and evaluating information or data to measure learners' progress and it is seen as a vehicle for motivating students learning (Bloxham \& Boyd, 2007). Currently assessment of learning (AoL) or summative assessment (SA) and assessment for learning (AfL) or formative assessment (FA) are adopted by Chinese Medical Education Council (CMEC) and medical schools to show how teachers have implemented the curriculum and how learners achieve the curriculum, to decide whether changes should be made to optimize the curriculum and to discriminate between students. In addition, assessment also serves as a means of providing institutional quality control assurance.

Summative assessment, usually a written test arranged at the end of a semester or year, is applied for the purpose of grading, evaluation or certification, in which test-takers only receive the achievement report without feedback (Figure 1). In other words, it is used for assessing learning outcomes; high stake tests by including closed-ended questions, such as multiple choice and true/false questions, open-ended questions, such as oral tests, and standardized tests. It can function well for the early stage of medical education when teachers, institutions and CMEC intend to assess medical students' core knowledge. However, the disadvantage becomes evident that it is hard for learners to develop their "critical thinking skills necessary for life as a Doctor" (Helina \& Dermot, 2015, p.141)

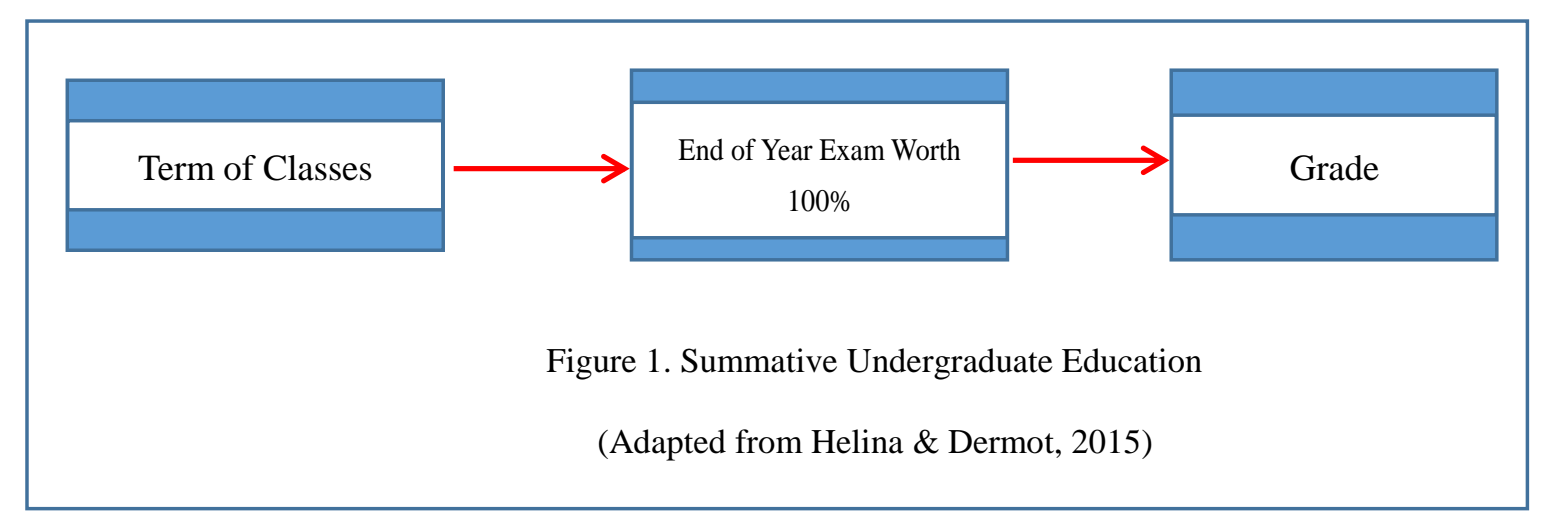

In the later medical years, formative assessment plan (Figure 2) is used in the form of closed-ended questions, such as multiple-choice questions and objective structured clinical examinations, and open-ended questions, such as essays, performance tasks, reflective portfolios and self/peer assessment, to provide feedback to students on their learning outcomes, which attempts to shift the focus from discrete competencies and isolated skills reflected through summative practices to professional skills reflected through formative practices. Due to the fact that they are more engaging and productive, many medical institutions incorporate more and more formative practices instead of summative practices. 


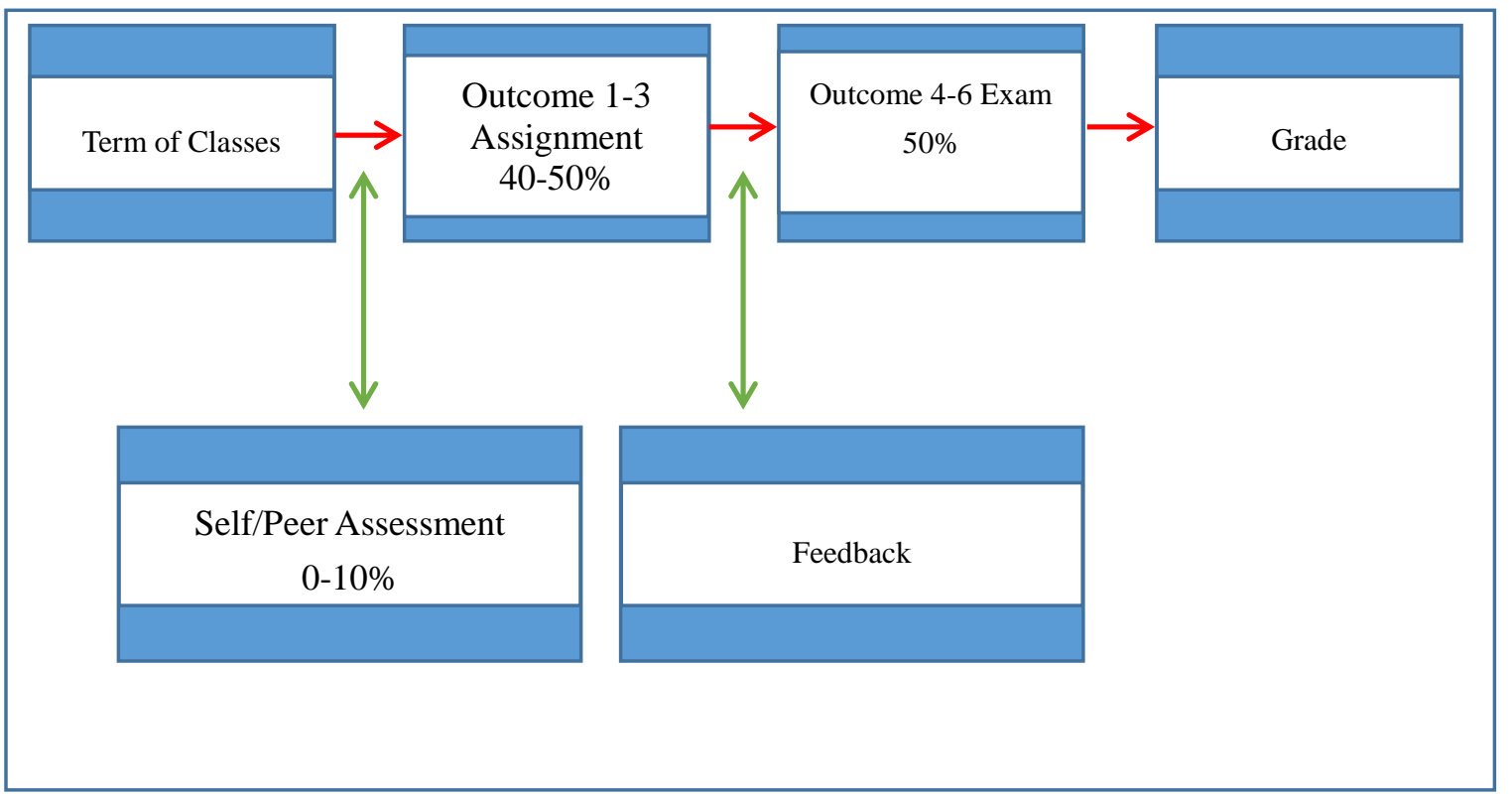

Figure 2. Formative Assessment Plan (Adapted from Dawson P.2014,Assessment as Learning)

Nowadays Chinese medical institutions stress emphasis on formative assessment by increasing its percentage from $20 \%$ to $50 \%$ primarily through quizzes and exams in order to equip medical students with the professionally needed skills to develop lifelong learning and critical thinking. The growing emphasis on formative assessment reflects educators' idea that providing feedback plays a significant role in adjusting and improving ongoing teaching and student learning (Kermal, 2016).

\section{Conclusion}

In the context of globalization, Chinese higher education faces unprecedented challenges and opportunities in many facets as its economy develops rapidly. Medical education as one inseparable part of Chinese higher education has a critical influence on people's life, both in providing qualified healthcare professionals and service. Under these circumstances, policymakers, curriculum developers and teachers pay growing attention to the quality of medical education that plays a significant role in sustaining the development by providing healthier labor force. It is evident that in the process of globalization new curricula in line with international standards tops the education agenda. Much effort has been made to plan the curriculum of medical science with international dimensions that train physicians for the health of individuals. This paper analyzes the characteristics of medical curricula in the facets of goals, content, teaching methods and assessment developed under new circumstances.

\section{References}

Abrahamson S. (1978). Diseases of the curriculum. J Med Educ., 1978 Dec, 53(12), 951-7. https://doi.org/10.1097/00001888-197812000-00001

Agbeh, A. (2014). The impact of problem-based learning on problem solving skills and a sense of community in the class room. Review of Higher Education and Self Learning, 6(24), 99-105.

Al-Rodhan N.R.F \& Stoudmann G. (2006). Definitions of Globalization: A Comprehensive Overview and a Proposed Definition. http://www.academia.edu/2969717/Definitions of Globalization A Comprehensive Overview and a The International Relations and Security Network ETH Zurich June 192006.

Balcioglu, H., Bilge, U., \& Unluoglu, I. (2015). A historical perspective of medical education. Journal of Education in Science, Environment and Health (JESEH), 1(2), 111-114.

Bloxham, S., \& Boyd, P. (2007). Developing Effective Assessment In Higher Education: A Practical Guide: McGraw-Hill International.

David P. H. \& Antonio M. G. (201)3. Launching of an American Medical College in the Middle East: Educational Challenges in a Multicultural Environment. International Journal of Higher Education, 2(2). 
Dawson P. Assessment as learning. ttps://www.youtube.com/watch?v=njgyYUNkyAs

Gibson-Graham, J. (2006). A Postcapitalist Politics. Minneapolis: University of Minnesota Press.

Green, A. (2006). 'National Education Systems and Comparative Educations: From State Formation to Globalisation'. In Pang, Nicholas Sun-Keung, Globalisation: Educational Research, Change and Reform. Hong Kong: The Chinese University of Hong Kong.

Helena F. \& Pauline J. (2015). Factors Influencing Curricular Reform; an Irish Perspective. International Journal of Higher Education, 4(2).

Helina F. \& Dermot O.F (2015). Assessment in Medical Education; What Are We Trying to Achieve? International Journal of Higher Education, 4(2).

Huang C.L. (2009). Research on Curriculum Provision of Eight-year Clinical Medical Education in Military Medical University. P.10

Huang R.Y. (2012). Trend and Change about Mode of Chinese Medical Education. Medicine and Philosophy, $33(11 \mathrm{~A})$.

Heritage, M. (2010). Formative Assessment and Next-Generation Assessment Systems: Are We Losing an Opportunity?. Council of Chief State School Officers.

Huseyin B, Ugur B \& Ilhami U. (2015). A Historical Perspective of Medical Education. Journal of Education in Science, Environment and Health, 1(2).

McGrath. D. L. (2007). Implementing an holistic approach in vocational education and training. Australian Journal of Adult Learning, 47(2).

Mcknight, Curtis C. (2000). Model for the Second International Mathematics Study. SIMS Bulletin 4, 6-39.

Mok, Ka-Ho. (2004). (Ed.). Centralization and Decentralization: Education Reforms and Changing Governance in Chinese Societies. Hong Kong: Kluwer Academic Publishers.

Huang R.Y. (2012). Trend and Change about Mode of Chinese Medical Education. Medicine and Philosophy, $33(11 \mathrm{~A})$.

Kemal Izci. (2016). International and External Factors Affecting Teachers Adoption of Formative Assessment to Support Learning. International Journal of Social, Behavioral, Educational, Economic, Business and Industrial Engineering, 10(8).

Slattery, P. (2006). Curriculum development in the postmodern era. New York: Routledge.

Stanger-Hall, K. F. (2012). Multiple-choice exams: An obstacle for higher-level thinking in introductory science classes. CBE Life Sciences Education, 11(3), 294-306. https://doi.org/10.1187/cbe.11-11-0100

William J. Flynn \& Jeff Vredevoogd. (2010). The Future of Learning: 12 Views on Emerging Trends in Higher Education. Planning for Higher Education, 38(2), 5-10. 